\title{
Relation between heart rate recovery index and syntax score
}

\author{
Sezen Bağlan Uzunget ${ }^{1 *}$, Eliz Kader Uzel' ${ }^{2}$, Özge Kurmuş ${ }^{1}$ and Berkay Ekici ${ }^{1}$ \\ ${ }^{1}$ Ankara Ufuk University Hospital, Faculty of Medicine, Cardiology Department, Turkey \\ ${ }^{2}$ Adiyaman University Education and Research Hospital, Department of Cardiology, Adiyaman, Turkey
}

\begin{abstract}
Background: Heart rate recovery is a function of vagal reactivation, and its impairment is an independent prognostic indicator for cardiovascular and all-cause mortality. We aimed to search relationship between heart rate recovery after exercise stress test and SYNTAX score.

Methods: This was a single-center retrospective cohort study. 346 individuals were included. Heart rate recovery index (HRRI) is defined as the reduction in heart rate from the rate at peak exercise to the rate at the $1^{\text {st }}, 2^{\text {nd }}$ and $3^{\text {rd }}$ minutes after the cessation of the exercise stress test, and these results were indicated as HRRI1, HRRI2 and HRRI3 respectively. The SYNTAX scores were calculated for all patients. The SYNTAX score was divided into tertiles as low ( $\leq 22)$, intermediate (23$32)$, and high ( $\geq 33)$.

Results: Compared to control group, patients with impaired HRRI1 had significantly higher SYNTAX scores while HRRI2 and HRRI3 demonstrated a marginally significant relation with high SYNTAX score. In bi-serial and partial correlational analyses, HRRI1, HRRI2 and HRRI3 were positively correlated with the high SYNTAX score $(r=-0.366, p<0.001 ; r=-0.313, p<0.001 ; r=-0.322, p<0.001)$. After adjustments were made for age, gender, hypertension, diabetes mellitus, hyperlipidemia and uric acid levels, HRRI1 was still significantly associated with high SYNTAX score $(r=-0.236,95 \%$ CI, $p=0.002)$, while the relationships between the high SYNTAX score and HRRI2 and HRRI3 lost significance $(r=-0.131, p=0.091 ; r=-0.159, p=0.040)$. ROC analyses showed HRRI 1,2 and 3 had moderate predictive ability for high SYNTAX score (AUC=0.713, 0.636-0.790, cut-off:22.5 bpm), (AUC=0.673, 0.593-0.752, cut-off:45.5 bpm) and (AUC=0.674, 0.5940.764 , cut-off: $60.5 \mathrm{bpm}$ ) respectively with CI $95 \%$.
\end{abstract}

Conclusions: A delayed decline of heart rate has been associated with increased risk of cardiovascular mortality. In our study lower heart rate recovery at first minute was associated with higher SYNTAX score.

\section{Introduction}

Exercise stress testing, which is now widely available at a relatively low cost, is currently used most frequently to estimate cardiovascular performance. Basically, it is performed to identify angina or electrocardiographic changes induced by exercise. Determining exercise capacity, chronotropic response, heart rate reserve, heart rate recovery index and ventricular ectopic beats, increases the value of the test.

Heart rate recovery (HRR) is a function of vagal reactivation, and its deterioration is an independent prognostic indicator for cardiovascular events and all-cause mortality. HRRI is calculated by extracting the heart rates at 1,2 and 3 minutes after cessation the test, from the patient's heart rate at finalizing the exercise. Many studies have shown that the HRRI in the 1st and 2nd minutes highly predicts prognosis in coronary artery patients and reported that those with impaired HRRI have a significantly higher risk of mortality [1-3].

SYNTAX score is an angiographic tool for grading the complexity of coronary artery disease according to the lesion number, lesion locations and functional importance. It was shown that SYNTAX scoring system could predict in-hospital, early and six months adverse cardiac outcomes $[4,5]$. Early prediction of mortality and morbidity enables taking precautions for complications in high risk patients.

In this study we aimed to search relationship between heart rate recovery index and SYNTAX score.

\section{Methods}

This was a single-center retrospective cohort study approved by the relevant Ethics Committee. All consecutive candidates that had had a coronary angiography within 30 days of exhibiting an abnormal exercise test result at our clinic, between January 2014 and December 2016, were enrolled. Of the subjects which we met the exercise test results on file scans, the ones reached the target heart rate were included in this study. The exclusion criteria were as follows: previous diagnosis of $\mathrm{CAD}$, myocardial infarction, slow coronary flow, previous revascularization, over 75 years old, inability to reach $85 \%$ of their age-predicted maximum heart rate in exercise test, presence of atrial fibrillation or flutter, history of chronic obstructive pulmonary disease, congestive heart failure, moderate to severe valvular heart disease, and the use of beta blocker (BB) medication, digoxin or calcium channel blockers. According to our inclusion and exclusion criteria we collected data on 346 subjects who exhibited ST depression and reached at least $85 \%$ of the age-predicted maximal heart rate during treadmill exercise test. Baseline demographic, clinical, and angiographic characteristics data and stress test results were retrieved from the patient files and the electronic centralized clinical database of our center. All angiographic parameters were calculated by an experienced cardiologist who was blinded to the procedural data. The SYNTAX score was derived

*Correspondence to: Sezen Bağlan Uzunget, MD, Ankara Ufuk University Hospital, Faculty of Medicine, Cardiology Department, Turkey, E-mail: sezenbaglan@hotmail.com

Key words: heart rate recovery index, coronary angiography, SYNTAX score

Received: September 24, 2018; Accepted: October 05, 2018; Published: October 08,2018 
from the summation of the individual scores for each separate lesion producing $\geq 50 \%$ luminal obstruction in vessels $\geq 1.5 \mathrm{~mm}$ diameter.

The SYNTAX scores were calculated for all patients using dedicated software (available at http://www.syntaxscore.com/calculator/start. $\mathrm{htm})$. Thereafter, the SYNTAX score was divided into tertiles as low $(\leq 22)$, intermediate (23-32), and high ( $\geq 33)$.

All patients in the study had underwent exercise treadmill testing using the Bruce protocol. In our clinical applications, patients do not perform a cool-down walk and are placed supine as soon as possible after exercise. The predicted peak heart rate was calculated as $(220-$ age), and the aim was to reach at least $85 \%$ of the age-predicted heart rates. The end of exercise was tagged, and at least 3 minutes of postexercise heart rate recorded with the subject at rest. Heart rate recovery indices were defined as the reduction in heart rate from the rate at finalizing exercise to the rate at the $1^{\text {st }}, 2^{\text {nd }}$ and $3^{\text {rd }}$ minutes after the cessation of the exercise stress test, and these results were indicated as HRRI1, HRRI2 and HRRI3 respectively.

\section{Statistical analysis}

Data analyses were performed by using SPSS for Windows, version 22.0 (SPSS Inc., Chicago, IL, United States). Whether the distribution of continuous variables was normal or not was determined by Kolmogorov Smirnov test. Levene test was used for the evaluation of homogeneity of variances. Unless specified otherwise, continuous data were described as mean $+/$ - SD for normal distributions, and median (minimum - maximum value) for skewed distributions. Categorical data were described as number of cases (\%).

While the differences in normally distributed variables among more than two independent groups were analyzed by One-Way ANOVA, otherwise, Kruskal Wallis test was applied for comparisons of the normally data. When the p-value from One-Way ANOVA or Kruskal Wallis test statistics were statistically significant post hoc LSD or Conover's non-parametric multiple comparison test were used to know which group differ from which others.

Univariate and multivariate logistic regression were used to determine predictors for SYNTAX score. Any variable having a significant univariate test at some arbitrary level is selected as a candidate for the multivariate analysis. We base this on the Wald test from logistic regression and $\mathrm{p}$-value cut-off point of 0.25 . Receiver Operating Characteristic (ROC) curve analysis was performed to detect the best sensitivity and specificity value of HRRI in predicting SYNTAX score.

\section{Results}

All patients and healthy participants had sinus rhythm and normal 12-lead ECG results at rest. The baseline characteristics of the study groups are shown in Table 1. Of the subjects, 251 (72.5\%) were male, 228 (65.9\%) had hypertension, and $125(36.1 \%)$ had diabetes mellitus.

Table 1. Demographic characteristics, risk factors, biochemical and exercise performance data of patients classified to SYNTAX score and control groups

\begin{tabular}{|c|c|c|c|c|c|c|}
\hline Variables & $\begin{array}{c}\text { Control group } \\
(\mathbf{n}: 87)\end{array}$ & $\begin{array}{c}\text { Lowest risk patients } \\
\text { (syntax score } \leq 22) \\
(\mathrm{n}: 80)\end{array}$ & $\begin{array}{c}\text { İntermediate risk } \\
\text { patients GI } \\
\text { (syntax score 23-32) } \\
\text { (n:92) }\end{array}$ & $\begin{array}{c}\text { Highest risk patients } \\
\text { GIII } \\
\text { (syntax score } \geq 33 \text { ) } \\
\text { (n:87) }\end{array}$ & Test statistic & p value \\
\hline Male Gender, n (\%) & $49(56.3)$ & $62(77.5)$ & $80(87.0)$ & $60(69.0)$ & $22.635^{t}$ & $<0.001$ \\
\hline Age, year & $55.01 \pm 9.58$ & $58.79 \pm 8.20$ & $63.85 \pm 9.26$ & $64.85 \pm 9.55$ & $21.806^{\Phi}$ & $<0.001 \mathrm{a}, \mathrm{b}, \mathrm{c}$ \\
\hline BMI, $\mathrm{kg} / \mathrm{m}^{2}$ & $29.13 \pm 6.18$ & $28.91 \pm 3.87$ & $28.05 \pm 4.05$ & $28.44 \pm 3.98$ & $0.961^{\Phi}$ & 0.411 \\
\hline Diabetes, n (\%) & $13(14.9)$ & $29(36.3)$ & $42(45.7)$ & $41(47.1)$ & $25.099^{\mathrm{t}}$ & $<0.001$ \\
\hline Hypertension, n (\%) & $42(48.3)$ & $49(61.3)$ & $68(73.9)$ & $69(79.3)$ & $22.385^{\mathrm{t}}$ & $<0.001$ \\
\hline Hyperlipidemia, n (\%) & $31(35.6)$ & $55(68.8)$ & $55(59.8)$ & $56(64.4)$ & $25.445^{t}$ & $<0.001$ \\
\hline Smoking, n (\%) & $36(41.4)$ & $41(51.3)$ & $46(50.0)$ & $53(60.9)$ & $6.684^{t}$ & 0.083 \\
\hline Uric asid, $\mathrm{mg} / \mathrm{dL}$ & $5.09 \pm 1.35$ & $5.66 \pm 1.43$ & $6.27 \pm 1.69$ & $6.19 \pm 1.69$ & $10.890^{\Phi}$ & $<0.001^{a, b, c, d, c}$ \\
\hline $\mathrm{Ldl}, \mathrm{mg} / \mathrm{dL}$ & $130.77 \pm 36.45$ & $124.17 \pm 39.60$ & $115.23 \pm 38.50$ & $128.92 \pm 39.04$ & $2.947^{\Phi}$ & $0.033^{\mathrm{c}, \mathrm{g}}$ \\
\hline $\mathrm{Hdl}, \mathrm{mg} / \mathrm{dL}$ & $45(25-97)$ & $40.51(22-136)$ & $38.85(20.50-104)$ & $40(19.20-60.80)$ & $15.124^{\beta}$ & $0.002^{a, b, c}$ \\
\hline Triglyceride, $\mathrm{mg} / \mathrm{dL}$ & $136(47-513)$ & $160.9(50-379)$ & $139.10(34-528)$ & $132(51.43-496)$ & $4.064^{\beta}$ & 0.255 \\
\hline Cholesterol, mg/dL & $204.02 \pm 47.88$ & $189.03 \pm 42.68$ & $182.11 \pm 45.23$ & $198.70 \pm 44.76$ & $4.158^{\Phi}$ & $0.007^{\mathrm{a}, \mathrm{b}, \mathrm{g}}$ \\
\hline Fasting glucose, $\mathrm{mg} / \mathrm{dL}$ & $103.98 \pm 19.29$ & $111.74 \pm 27.12$ & $113.63 \pm 33.60$ & $134.77 \pm 60.54$ & $10.142^{\Phi}$ & $<0.001^{\mathrm{c}, \mathrm{e}, \mathrm{g}}$ \\
\hline Creatinine, $\mathrm{mg} / \mathrm{dL}$ & $0.76(0.07-5)$ & $0.88(0.56-7)$ & $0.97(0.48-2.77)$ & $0.95(0.64-48)$ & $46.494^{\beta}$ & $<0.001 \mathrm{a}$ a, b, c \\
\hline Duration of the exercise period,min & $9.23 \pm 5.77$ & $8.17 \pm 2.12$ & $6.80 \pm 3.52$ & $7.04 \pm 1.50$ & $8.227^{\Phi}$ & $<0.001^{a, b, c, e}$ \\
\hline Resting SBP, $\mathrm{mm} \mathrm{Hg}$ & $120(90-150)$ & $120(90-175)$ & $120(90-160)$ & $130(100-160)$ & $12.933^{\beta}$ & $0.005^{\mathrm{e}}$ \\
\hline Resting DBP, $\mathrm{mm} \mathrm{Hg}$ & $80(50-90)$ & $80(50-110)$ & $80(50-100)$ & $80(50-100)$ & $0.207^{\beta}$ & 0.976 \\
\hline Peak SBP, mm Hg & $160(110-220)$ & $160(120-220)$ & $160(110-220)$ & $170(130-200)$ & $5.002^{\beta}$ & 0.172 \\
\hline Peak DBP, $\mathrm{mm} \mathrm{Hg}$ & $90(60-110)$ & $80(9.90-110)$ & $89(9.90-110)$ & $90(60-110)$ & $2.611^{\beta}$ & 0.456 \\
\hline METs, unit & $10.90(3.59-14.80)$ & $9.95(5.20-129)$ & $9.90(4-13.91)$ & $9.90(4-13.91)$ & $20.273^{\beta}$ & $<0.001^{\mathrm{b}, \mathrm{c}, \mathrm{d}, \mathrm{e}}$ \\
\hline Resting heart rate, bpm & $79.97 \pm 17.12$ & $84.94 \pm 16.68$ & $83.85 \pm 14.52$ & $82.90 \pm 16.44$ & $11.077^{\Phi}$ & $<0.001^{\mathrm{a}, \mathrm{b}, \mathrm{c}, \mathrm{d}, \mathrm{e}}$ \\
\hline Peak heart rate, bpm & $148.82 \pm 16.96$ & $152.19 \pm 15.25$ & $146.62 \pm 16.81$ & $139.55 \pm 16.75$ & $9.409^{\Phi}$ & $<0.001^{\mathrm{c}, \mathrm{d}, \mathrm{e}, \mathrm{g}}$ \\
\hline HRRI1, bpm & $27.49 \pm 10.54$ & $26.46 \pm 9.89$ & $22.98 \pm 7.74$ & $20.46 \pm 7.13$ & $11.378^{\Phi}$ & $<0.001^{b, c, d, e}$ \\
\hline HRRI2, bpm & $47.60 \pm 12.38$ & $47.82 \pm 14.25$ & $43.96 \pm 12.60$ & $39.90 \pm 11.09$ & $7.499^{\Phi}$ & $<0.001 \mathrm{c}, \mathrm{d}, \mathrm{e}, \mathrm{g}$ \\
\hline HRRI3, bpm & $55.93 \pm 14.28$ & $53.39 \pm 14.58$ & $51.16 \pm 13.48$ & $47.15 \pm 11.55$ & $6.589^{\Phi}$ & $0.001^{b, c, e, g}$ \\
\hline ACE & $6(6.9)$ & $12(15.0)$ & $12(13.0)$ & $10(11.5)$ & $2.975^{t}$ & 0.396 \\
\hline
\end{tabular}

Severity of coronary artery diseases was determined by SYNTAX Score. Data are expressed as mean \pm standard deviation or median (minimum-maximum) for continuous variables and number (percentage) for categorical variables; $\Phi$ : One way Anova test, $\beta$ : Kruskal wallis test and t: Chi-square; least significant difference (LSD) or conover-Inman test were performed for the binary comparisons among the groups and the $\mathrm{p}$ value was set at 0.05 . Significant differences were found between; a: C vs GI, b: C vs GII, c: C vs GIII, d: GI vs GII, e: GI vs GIII, g: GII vs GIII; BMI - body mass index; LDL - low-density lipoprotein; HDL - high density lipoprotein; SBP - systolic blood pressure; DBP - diastolic blood pressure; METs - metabolic equivalent; bpm - beat per minute; HRRI1 - heart rate recovery index at first minute; HRRI2 - heart rate recovery index at second minute; HRRI3 - heart rate recovery index at third minute; ACE - accreditation for cardiovascular excellence; mm- millimeter. 
All 346 subjects were categorized into 4 groups based on SYNTAX scores: control group, low ( $\leq 22)$, intermediate (23-32), and high $(\geq 33)$ SYNTAX score. Significant differences for gender, DM and HT status were found between four groups. The binary comparisons of these four groups for HRRI1, HRRI2 and HRRI3, also demonstrated statistically significant differences $(\mathrm{p}<0.001)$. Fasting glucose and serum creatinine levels, duration of the exercise period and the workload in METS were statistically significant in some of the binary comparisons. Univariate analyses of each risk factor for predicting SYNTAX scores were performed. Because of high correlation between HRRI1, 2 and 3, influence of each of them was assessed separately. Any variable having a significant univariate test $(\mathrm{p}<0.25)$ was selected as a candidate for the multivariate analysis (Tables 2-4). Mean HRRI1, 2 and 3 durations of control group and SYNTAX groups are shown in Figure 1. Mean reduction in heart rate declines as the severity of CAD increases. However, there were no statistically significant correlation between HRRI indices and the low and intermediate SYNTAX scores. Univariate and multivariate analyses for HRRI2 and HRRI3 demonstrated a marginally significant relation with high SYNTAX score (39.90 \pm 11.09 vs $47.60 \pm 12.38 \mathrm{p}=0.067$ and $47.15 \pm 11.55$ vs $55.93 \pm 14.28 \mathrm{p}=0.063$ respectively) and analysis for HRRI1 showed a statistically significant relation $(20.46 \pm 7.13$ vs $27.49 \pm 10.54 \mathrm{p}=0.002)$. Cardiovascular disease risk factors such as age, hypertension, uric acid level and diabetes mellitus also correlated with the high SYNTAX scores. To control their effects partial correlation analysis was performed (Table 5).

\section{Results of ROC analysis}

Figures 2, 3 \& 4: ROC curve analyses for predictive values of HRRI in detecting CAD severity evaluated by SYNTAX score.In the low SYNTAX ( $\leq 22)$ group; no cut-offs were given for HRRI1, HRRI2 and HRRI3 due to all of the asymptotic significances were greater than 0.5 (Figure 2).

In the intermediate SYNTAX group (23-32); asymptotic significance for HRRI 2 was greater than 0.5 , so only cut offs for HRRI 1 and HRRI3 were calculated (Figure 3). (AUC=0.627, 0.545-0.708, cut-off:22.5 bps) and (AUC=0.588, 0.504-0.671, cut-off:60.5 bps) respectively with $\mathrm{CI}$ $95 \%$.

In the high SYNTAX group( $\geq 33)$; HRRI 1,2 and 3 showed a moderate predictive ability for high SYNTAX score according to the area under the ROC curve (AUC=0.713, 0.636-0.790, with $75.9 \%$ sensitivity and $66.7 \%$ specificity, cut-off:22.5 bps), (AUC=0.673, 0.593 -

Table 2. Univariate and multivariate analyses of HRRI1 and variables associated with CAD in three SYNTAX groups

\begin{tabular}{|c|c|c|c|c|c|c|c|c|}
\hline & \multicolumn{4}{|c|}{ Univariate Analysis } & \multicolumn{4}{|c|}{ Multivariate Analysis } \\
\hline & Wald & OR & $\% 95$ CI & P value & Wald & OR & $\% 95$ CI & P value \\
\hline \multicolumn{9}{|c|}{$\begin{array}{l}\text { Low }(\leq 22) \text { SYNTAX } \\
\text { Score patients }\end{array}$} \\
\hline Gender & 8.153 & 2.671 & 1.361 to 5.243 & 0.004 & & & & \\
\hline Age & 6.889 & 1.049 & 1.012 to 1.087 & 0.009 & & & & \\
\hline BMI & 0.077 & 0.992 & 0.935 to 1.052 & 0.781 & & & & \\
\hline Diabetes & 9.546 & 3.237 & 1.536 to 6.819 & 0.002 & & & & \\
\hline Hypertension & 2.812 & 1.694 & 0.915 to 3.135 & 0.094 & & & & \\
\hline Hyperlipidemia & 17.580 & 3.974 & 2.085 to 7.575 & $<0.001$ & & & & \\
\hline Smoking & 1.629 & 1.489 & 0.808 to 2.746 & 0.202 & & & & \\
\hline Uric acid & 6.508 & 1.350 & 1.072 to 1.699 & 0.011 & & & & \\
\hline $\mathrm{ACE}$ & 2.720 & 2.382 & 0.849 to 6.684 & 0.099 & & & & \\
\hline HRRI1 & 0.427 & 0.990 & 0.961 to 1.020 & 0.514 & & & & \\
\hline \multicolumn{9}{|c|}{$\begin{array}{l}\text { Intermediate (23-32) SYNTAX Score } \\
\text { patients }\end{array}$} \\
\hline Gender & 18.933 & 5.170 & 2.467 to 10.836 & $<0.001$ & 10.041 & 5.930 & 1.972 to 17.832 & 0.002 \\
\hline Age & 27.353 & 1.105 & 1.064 to 1.147 & $<0.001$ & 11.174 & 1.082 & 1.033 to 1.134 & 0.001 \\
\hline BMI & 1.843 & 0.959 & 0.903 to 1.019 & 0.175 & 2.109 & 0.937 & 0.858 to 1.023 & 0.146 \\
\hline Diabetes & 18.239 & 4.782 & 2.332 to 9.805 & $<0.001$ & 6.885 & 3.582 & 1.381 to 9.290 & 0.009 \\
\hline Hypertension & 12.041 & 3.036 & 1.621 to 5.684 & 0.001 & 3.735 & 2.352 & 0.988 to 5.599 & 0.053 \\
\hline Hyperlipidemia & 10.236 & 2.685 & 1.466 to 4.918 & 0.001 & 1.672 & 1.714 & 0.757 to 3.878 & 0.196 \\
\hline Smoking & 1.335 & 1.417 & 0.785 to 2.558 & 0.248 & 0.065 & 1.113 & 0.487 to 2.542 & 0.799 \\
\hline Uric acid & 20.177 & 1.674 & 1.337 to 2.097 & $<0.001$ & 12.177 & 1.657 & 1.248 to 2.201 & $<0.001$ \\
\hline $\mathrm{ACE}$ & 1.811 & 2.025 & 0.725 to 5.658 & 0.178 & 3.896 & 4.057 & 1.010 to 16.295 & 0.048 \\
\hline HRRI1 & 9.596 & 0.947 & 0.916 to 0.980 & 0.002 & 0.074 & 0.993 & 0.945 to 1.044 & 0.786 \\
\hline \multicolumn{9}{|c|}{$\begin{array}{l}\text { High }(\geq 33) \text { SYNTAX } \\
\text { Score patients }\end{array}$} \\
\hline Gender & 2.950 & 1.163 & 0.926 to 3.207 & 0.086 & 2.672 & 2.294 & 0.848 to 6.209 & 0.102 \\
\hline Age & 29.458 & 1.115 & 1.072 to 1.160 & $<0.001$ & 17.971 & 1.114 & 1.060 to 1.171 & $<0.001$ \\
\hline BMI & 0.767 & 0.974 & 0.918 to 1.033 & 0.381 & & & & \\
\hline Diabetes & 19.313 & 5.074 & 2.459 to 10.468 & $<0.001$ & 3.984 & 2.628 & 1.018 to 6.787 & 0.046 \\
\hline Hypertension & 17.193 & 4.107 & 2.106 to 8.008 & $<0.001$ & 3.163 & 2.240 & 0.921 to 5.447 & 0.075 \\
\hline Hyperlipidemia & 13.956 & 3.263 & 1.755 to 6.069 & $<0.001$ & 2.728 & 2.087 & 0.872 to 4.997 & 0.099 \\
\hline Smoking & 6.561 & 2.208 & 1.204 to 4.049 & 0.010 & 2.425 & 2.012 & 0.835 to 4.848 & 0.119 \\
\hline Uric acid & 17.920 & 1.620 & 1.296 to 2.025 & $<0.001$ & 4.341 & 1.380 & 1.019 to 1.869 & 0.037 \\
\hline ACE & 1.080 & 1.753 & 0.608 to 5.056 & 0.299 & & & & \\
\hline HRRI1 & 19.609 & 0.912 & 0.876 to 0.950 & $<0.001$ & 9.789 & 0.910 & 0.858 to 0.965 & 0.002 \\
\hline
\end{tabular}

CI (95\%); confidence; OR: odds ratio; Variable excluded of multivariate analysis since presented $\mathrm{p}>0.25$ in univariate analysis. 
Table 3. Univariate and multivariate analyses of HRRI 2 and variables associated with CAD in three SYNTAX groups

\begin{tabular}{|c|c|c|c|c|c|c|c|c|}
\hline & \multicolumn{4}{|c|}{ Univariate Analysis } & \multicolumn{4}{|c|}{ Multivariate Analysis } \\
\hline & Wald & OR & $\% 95$ CI & P value & Wald & OR & $\% 95$ CI & P value \\
\hline \multicolumn{9}{|c|}{$\begin{array}{l}\text { Low }(\leq 22) \text { SYNTAX } \\
\text { Score patients }\end{array}$} \\
\hline Gender & 8.153 & 2.671 & 1.361 to 5.243 & 0.004 & & & & \\
\hline Age & 6.889 & 1.049 & 1.012 to 1.087 & 0.009 & & & & \\
\hline BMI & 0.077 & 0.992 & 0.935 to 1.052 & 0.781 & & & & \\
\hline Diabetes & 9.546 & 3.237 & 1.536 to 6.819 & 0.002 & & & & \\
\hline Hypertension & 2.812 & 1.694 & 0.915 to 3.135 & 0.094 & & & & \\
\hline Hyperlipidemia & 17.580 & 3.974 & 2.085 to 7.575 & $<0.001$ & & & & \\
\hline Smoking & 1.629 & 1.489 & 0.808 to 2.746 & 0.202 & & & & \\
\hline Uric acid & 6.508 & 1.350 & 1.072 to 1.699 & 0.011 & & & & \\
\hline $\mathrm{ACE}$ & 2.720 & 2.382 & 0.849 to 6.684 & 0.099 & & & & \\
\hline HRRI2 & 0.012 & 1.001 & 0.979 to 1.025 & 0.912 & & & & \\
\hline \multicolumn{9}{|c|}{$\begin{array}{l}\text { Intermediate (23-32) } \\
\text { SYNTAX Score patients }\end{array}$} \\
\hline Gender & 18.933 & 5.170 & 2.467 to 10.836 & $<0.001$ & 12.365 & 6.598 & 6.598 to 18.884 & $<0.001$ \\
\hline Age & 27.353 & 1.105 & 1.064 to 1.147 & $<0.001$ & 11.747 & 1.085 & 1.085 to 1.137 & 0.001 \\
\hline BMI & 1.843 & 0.959 & 0.903 to 1.019 & 0.175 & 1.991 & 0.939 & 0.939 to 1.025 & 0.158 \\
\hline Diabetes & 18.239 & 4.782 & 2.332 to 9.805 & $<0.001$ & 7.811 & 3.939 & 3.939 to 10.302 & 0.005 \\
\hline Hypertension & 12.041 & 3.036 & 1.621 to 5.684 & 0.001 & 3.611 & 2.322 & 2.322 to 5.535 & 0.057 \\
\hline Hyperlipidemia & 10.236 & 2.685 & 1.466 to 4.918 & 0.001 & 2.112 & 1.849 & 1.849 to 4.233 & 0.146 \\
\hline Smoking & 1.335 & 1.417 & 0.785 to 2.558 & 0.248 & 0.016 & 1.056 & 1.056 to 2.442 & 0.898 \\
\hline Uric acid & 20.177 & 1.674 & 1.337 to 2.097 & $<0.001$ & 12.577 & 1.669 & 1.669 to 2.214 & $<0.001$ \\
\hline ACE & 1.811 & 2.025 & 0.725 to 5.658 & 0.178 & 4.096 & 4.158 & 4.158 to 16.527 & 0.043 \\
\hline HRRI2 & 3.688 & 0.977 & 0.954 to 1.000 & 0.055 & 0.460 & 1.012 & 1.012 to 1.048 & 0.498 \\
\hline \multicolumn{9}{|c|}{$\begin{array}{l}\text { High }(\geq 33) \text { SYNTAX } \\
\text { Score patients }\end{array}$} \\
\hline Gender & 2.950 & 1.163 & 0.926 to 3.207 & 0.086 & 2.260 & 2.097 & 0.799 to 5.504 & 0.133 \\
\hline Age & 29.458 & 1.115 & 1.072 to 1.160 & $<0.001$ & 16.435 & 1.103 & 1.052 to 1.156 & $<0.001$ \\
\hline BMI & 0.767 & 0.974 & 0.918 to 1.033 & 0.381 & & & & \\
\hline Diabetes & 19.313 & 5.074 & 2.459 to 10.468 & $<0.001$ & 4.491 & 2.814 & 1.081 to 7.327 & 0.034 \\
\hline Hypertension & 17.193 & 4.107 & 2.106 to 8.008 & $<0.001$ & 2.992 & 2.169 & 0.902 to 5.213 & 0.084 \\
\hline Hyperlipidemia & 13.956 & 3.263 & 1.755 to 6.069 & $<0.001$ & 3.028 & 2.118 & 0.910 to 4.932 & 0.082 \\
\hline Smoking & 6.561 & 2.208 & 1.204 to 4.049 & 0.010 & 2.517 & 2.001 & 0.849 to 4.716 & 0.113 \\
\hline Uric acid & 17.920 & 1.620 & 1.296 to 2.025 & $<0.001$ & 5.777 & 1.436 & 1.069 to 1.930 & 0.016 \\
\hline ACE & 1.080 & 1.753 & 0.608 to 5.056 & 0.299 & & & & \\
\hline HRRI2 & 15.474 & 0.945 & 0.919 to 0.972 & $<0.001$ & 3.360 & 0.967 & 0.933 to 1.002 & 0.067 \\
\hline
\end{tabular}

CI (95\%); confidence; OR: odds ratio; Variable excluded of multivariate analysis since presented $\mathrm{p}>0.25$ in univariate analysis.

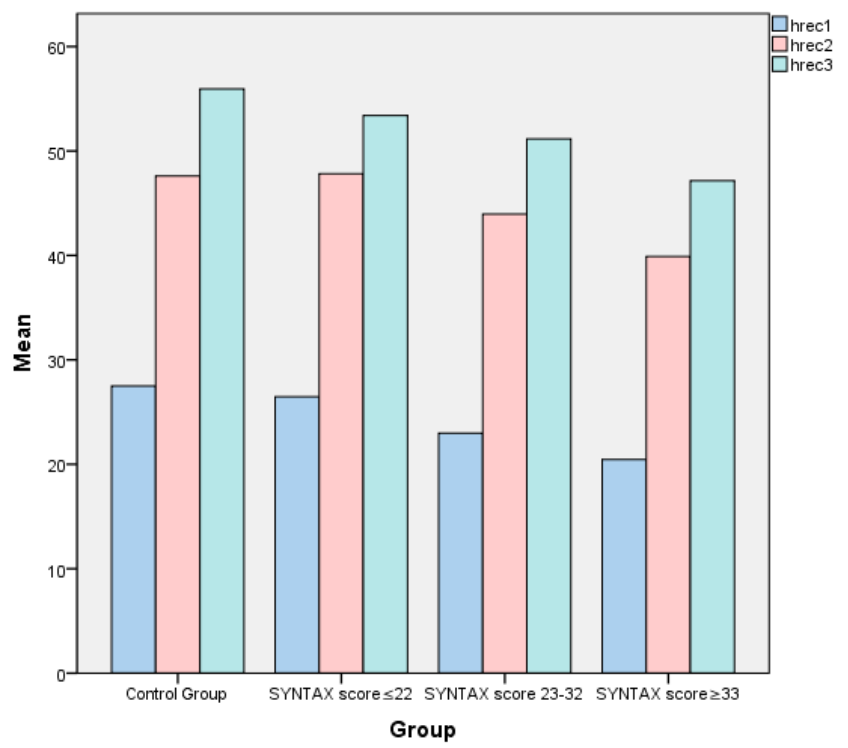

Figure 1. Mean HRRI1, 2 and 3 durations of control group and SYNTAX groups 
Table 4. Univariate and multivariate analyses of HRRI3 and variables associated with CAD in three SYNTAX groups

\begin{tabular}{|c|c|c|c|c|c|c|c|c|}
\hline & \multicolumn{4}{|c|}{ Univariate Analysis } & \multicolumn{4}{|c|}{ Multivariate Analysis } \\
\hline & Wald & OR & $\% 95$ CI & P value & Wald & OR & $\% 95$ CI & P value \\
\hline \multicolumn{9}{|c|}{$\begin{array}{l}\text { Low }(\leq 22) \text { SYNTAX } \\
\text { Score patients }\end{array}$} \\
\hline Gender & 8.153 & 2.671 & 1.361 to 5.243 & 0.004 & & & & \\
\hline Age & 6.889 & 1.049 & 1.012 to 1.087 & 0.009 & & & & \\
\hline BMI & 0.077 & 0.992 & 0.935 to 1.052 & 0.781 & & & & \\
\hline Diabetes & 9.546 & 3.237 & 1.536 to 6.819 & 0.002 & & & & \\
\hline Hypertension & 2.812 & 1.694 & 0.915 to 3.135 & 0.094 & & & & \\
\hline Hyperlipidemia & 17.580 & 3.974 & 2.085 to 7.575 & $<0.001$ & & & & \\
\hline Smoking & 1.629 & 1.489 & 0.808 to 2.746 & 0.202 & & & & \\
\hline Uric acid & 6.508 & 1.350 & 1.072 to 1.699 & 0.011 & & & & \\
\hline $\mathrm{ACE}$ & 2.720 & 2.382 & 0.849 to 6.684 & 0.099 & & & & \\
\hline HRRI3 & 1.289 & 0.988 & 0.967 to 1.009 & 0.256 & & & & \\
\hline \multicolumn{9}{|c|}{$\begin{array}{l}\text { Intermediate (23-32) } \\
\text { SYNTAX Score patients }\end{array}$} \\
\hline Gender & 18.933 & 5.170 & 2.467 to 10.836 & $<0.001$ & 11.788 & 6.148 & 2.180 to 17.337 & 0.001 \\
\hline Age & 27.353 & 1.105 & 1.064 to 1.147 & $<0.001$ & 11.208 & 1.082 & 1.033 to 1.133 & 0.001 \\
\hline BMI & 1.843 & 0.959 & 0.903 to 1.019 & 0.175 & 2.195 & 0.935 & 0.856 to 1.022 & 0.138 \\
\hline Diabetes & 18.239 & 4.782 & 2.332 to 9.805 & $<0.001$ & 6.631 & 3.505 & 1.349 to 9.107 & 0.010 \\
\hline Hypertension & 12.041 & 3.036 & 1.621 to 5.684 & 0.001 & 3.880 & 2.424 & 1.004 to 5.849 & 0.049 \\
\hline Hyperlipidemia & 10.236 & 2.685 & 1.466 to 4.918 & 0.001 & 1.681 & 1.712 & 0.759 to 3.861 & 0.195 \\
\hline Smoking & 1.335 & 1.417 & 0.785 to 2.558 & 0.248 & 0.090 & 1.136 & 0.494 to 2.613 & 0.765 \\
\hline Uric acid & 20.177 & 1.674 & 1.337 to 2.097 & $<0.001$ & 12.016 & 1.654 & 1.244 to 2.197 & 0.001 \\
\hline ACE & 1.811 & 2.025 & 0.725 to 5.658 & 0.178 & 3.624 & 3.889 & .961 to 15.742 & 0.057 \\
\hline HRRI3 & 4.997 & 0.975 & 0.954 to 0.997 & 0.025 & 0.184 & 0.993 & .959 to 1.027 & 0.668 \\
\hline \multicolumn{9}{|c|}{$\begin{array}{l}\text { High }(\geq 33) \text { SYNTAX } \\
\text { Score patients }\end{array}$} \\
\hline Gender & 2.950 & 1.163 & 0.926 to 3.207 & 0.086 & 2.819 & 2.288 & 0.871 to 6.015 & 0.093 \\
\hline Age & 29.458 & 1.115 & 1.072 to 1.160 & $<0.001$ & 16.387 & 1.102 & 1.051 to 1.155 & $<0.001$ \\
\hline BMI & 0.767 & 0.974 & 0.918 to 1.033 & 0.381 & & & & \\
\hline Diabetes & 19.313 & 5.074 & 2.459 to 10.468 & $<0.001$ & 5.052 & 2.974 & 1.150 to 7.693 & 0.025 \\
\hline Hypertension & 17.193 & 4.107 & 2.106 to 8.008 & $<0.001$ & 4.137 & 2.457 & 1.033 to 5.844 & 0.042 \\
\hline Hyperlipidemia & 13.956 & 3.263 & 1.755 to 6.069 & $<0.001$ & 3.831 & 2.307 & .999 to 5.328 & 0.049 \\
\hline Smoking & 6.561 & 2.208 & 1.204 to 4.049 & 0.010 & 2.120 & 1.889 & .802 to 4.445 & 0.145 \\
\hline Uric acid & 17.920 & 1.620 & 1.296 to 2.025 & $<0.001$ & 6.720 & 1.479 & 1.100 to 1.988 & 0.010 \\
\hline $\mathrm{ACE}$ & 1.080 & 1.753 & 0.608 to 5.056 & 0.299 & & & & \\
\hline HRRI3 & 4.063 & 0.977 & 0.956 to 0.999 & 0.044 & 3.459 & 0.984 & 0.968 to 1.001 & 0.063 \\
\hline
\end{tabular}

CI (95\%); confidence; OR: odds ratio; Variable excluded of multivariate analysis since presented $\mathrm{p}>0.25$ in univariate analysis.

Table 5. Bi-serial and Partial Correlation Analyses for HRRI and SYNTAX Score Relationship

\begin{tabular}{|c|c|c|c|c|c|c|}
\hline \multirow{2}{*}{ SYNTAX SCORE: } & \multicolumn{2}{|c|}{ HRRI1 } & \multicolumn{2}{|c|}{ HRRI2 } & \multicolumn{2}{|c|}{ HRRI3 } \\
\hline & $\mathbf{r}$ & $\mathbf{p}$ & $\mathbf{r}$ & $\mathbf{p}$ & $\mathbf{r}$ & $\mathbf{p}$ \\
\hline \multicolumn{7}{|l|}{$\leq 22,(\mathrm{n}: 80)$} \\
\hline None control variables & -0.051 & 0.516 & 0.009 & 0.912 & -0.088 & 0.257 \\
\hline Control variables are age, gender,DM, HT, HL, uric acid & 0.050 & 0.530 & 0.113 & 0.154 & -0.007 & 0.930 \\
\hline \multicolumn{7}{|l|}{$23-32,(n: 92)$} \\
\hline None control variables & -0.239 & 0.001 & -0.145 & 0.053 & -0.170 & 0.023 \\
\hline Control variables are age, gender,DM, HT, HL, uric acid & -0.023 & 0.761 & 0.030 & 0.693 & -0.039 & 0.611 \\
\hline \multicolumn{7}{|l|}{$\geq 33,(\mathrm{n}: 87)$} \\
\hline None control variables & -0.366 & $<0.001$ & -0.313 & $<0.001$ & -0.322 & $<0.001$ \\
\hline Control variables are age, gender,DM, HT, HL, uric acid & -0.236 & 0.002 & -0.131 & 0.091 & -0.159 & 0.040 \\
\hline
\end{tabular}

0.752 , with $74.7 \%$ sensitivity and $52.9 \%$ specificity, cut-off: $45.5 \mathrm{bps}$ ) and (AUC $=0.674,0.594-0.764$, with $93.1 \%$ sensitivity and $41.4 \%$ specificity, cut-off:60.5 bps) respectively with CI 95\% (Figure 4).

\section{Results of Correlation analysis}

We also used point bi-serial correlation analysis to assess the relationship between HRRI and SYNTAX score. No relationship was found between HRRI1, HRRI2 and HRRI3 and the low SYNTAX score
( $p=0.516,0.912$ and 0.257 resp). HRRI1 and HRRI3 had significant relationship ( $\mathrm{p}=0.001$ and $\mathrm{p}=0.023$ respectively) and HRRI2 had moderate relationship ( $\mathrm{p}=0.053$ ) with the intermediate SYNTAX score, however, the statistical significances were lost after partial correlational analysis, controlling for age, gender, hypertension, diabetes mellitus, hyperlipidemia and uric acid ( $\mathrm{p}=0.761, \mathrm{p}=0.693, \mathrm{p}=0.611$ resp). HRRI1, HRRI2 and HRRI3 were positively correlated with the high SYNTAX score $(\mathrm{r}=-0.366, \mathrm{p}<0.001 ; \mathrm{r}=-0.313, \mathrm{p}<0.001 ; \mathrm{r}=-0.322$, 


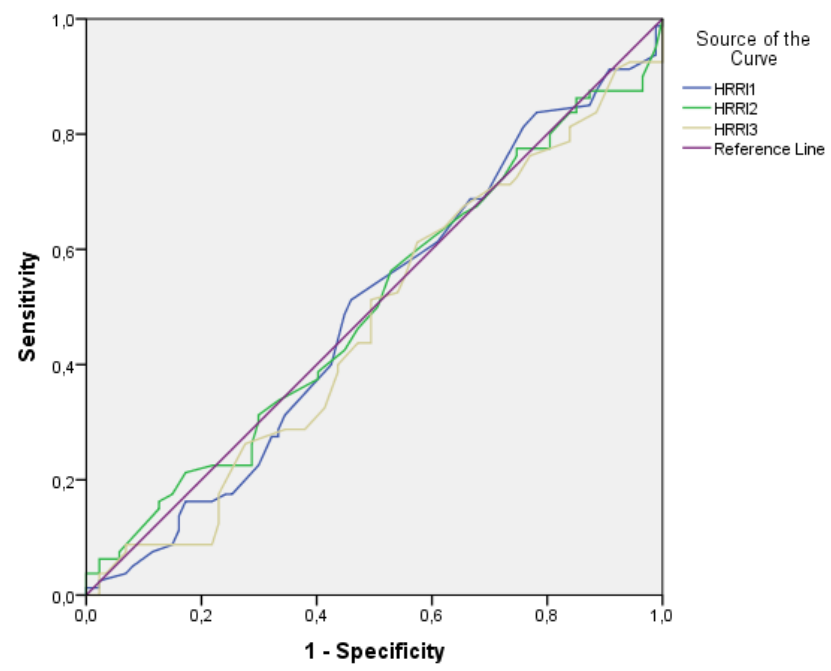

Figure 2. Cut-off values for HRRI 1,2,3 in Low SYNTAX Score Group In the low SYNTAX $(\leq 22)$ group; no cut-offs were given for HRRI1, HRRI2 and HRRI3 due to all of the asymptotic significances were greater than 0.5 .

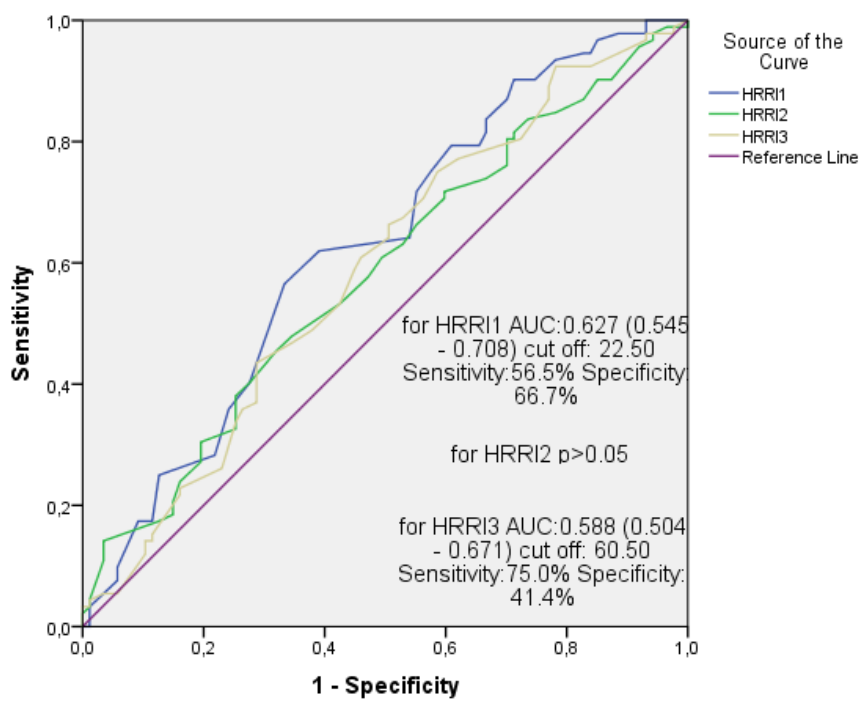

Figure 3. Cut-off values for HRRI 1,2,3 in Intermediate SYNTAX Score Group

In the intermediate SYNTAX group (23-32); asymptotic significance for HRRI 2 was greater than 0.5, so only cut offs for HRRI1 and HRRI3 were calculated (Figure 3). (AUC=0.627, $0.545-0.708$, cut-off: $22.5 \mathrm{bps}$ ) and (AUC=0.588, 0.504-0.671, cut-off: 60.5 bps) respectively with CI $95 \%$.

$\mathrm{p}<0.001)$. After adjustment of all other independent variables, HRRI1 was still significantly associated with high SYNTAX score $(r=-0.236$, 95\% CI, $\mathrm{p}=0.002$ ) while the relationships between the high SYNTAX score and HRRI2 and HRRI3 lost significance $(\mathrm{r}=-0.131, \mathrm{p}=0.091 ; \mathrm{r}$ $=-0.159, \mathrm{p}=0.040)($ Table 5$)$.

\section{Discussion}

Coronary artery disease (CAD) is the leading cause of morbidity and mortality in many developed countries [6]. Scientists and researchers have concentrated to reduce the burden by enhancing new identification and treatment strategies. Besides it is inexpensive and noninvasive, due to its reliability, exercise stress test is the initial test employed in the diagnosis of CAD. Exercise testing has been suggested to be valuable and less dependent on the patient's pre-test possibility for the purpose of risk stratification $[7,8]$. While evaluating a stress test, ST segment deviation, exercise hypotension or hypertension, maximum exercise capacity, chronotropic response to exercise, heart rate variability and heart rate recovery are the parameters that have been shown to carry prognostic values [9-15]. Several studies have attempted to determine exercise test scores that incorporate clinical and demographic risk factors not based on the exercise test itself An example of such is the Duke Treadmill Score. In a latest study by Dzenkeviciute et al., a negative correlation between Duke treadmill score and significant coronary artery stenosis $(\mathrm{r}=-0.181, \mathrm{p}=0.005)$, SYNTAX score $(\mathrm{r}=-0.173 ; \mathrm{p}=0.007)$, cardiac revascularizations $(\mathrm{r}=-$ $0.213 ; \mathrm{p}=0.001$ ) were found, however, its significance to predict cardiac revascularization was dependent on confounding clinical findings [16].

There is considerable recent evidence that heart rate recovery is an important parameter thought to reflect the cardiac autonomic nervous system function [17]. Changes in heart rate during and following exercise 


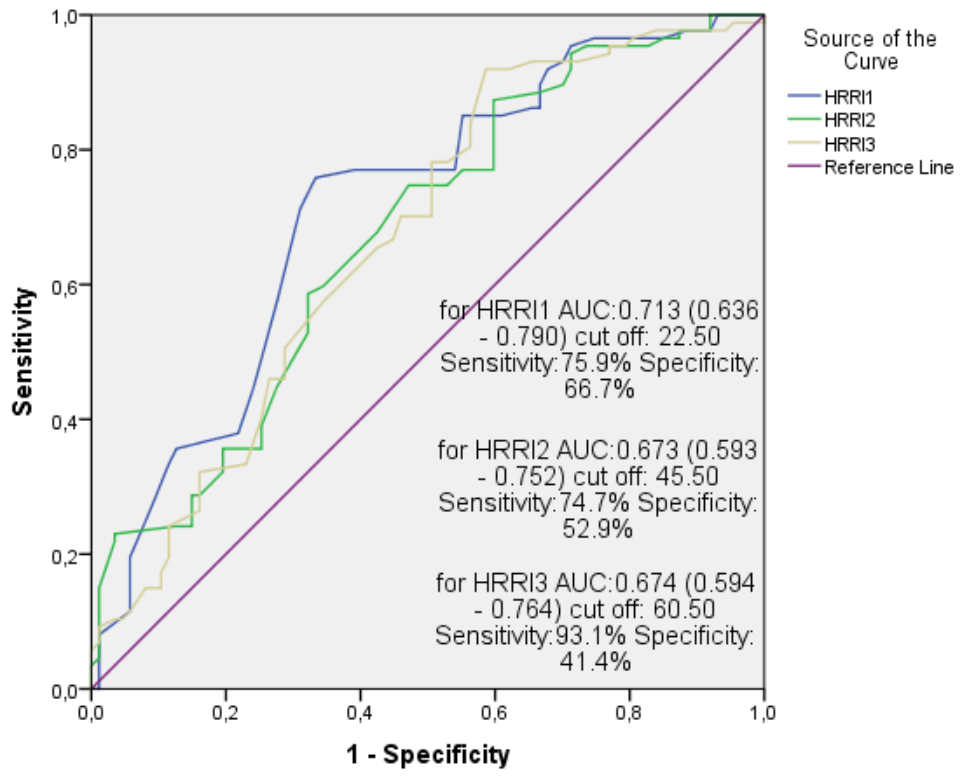

Figure 4. Cut-off values for HRRI 1,2,3 in High SYNTAX Score Group

In the high SYNTAX group( $\geq 33$ ); HRRI 1,2 and 3 showed a moderate predictive ability for high SYNTAX score according to the area under the ROC curve $(A U C=0.713,0.636-0.790$, with $75.9 \%$ sensitivity and $66.7 \%$ specificity, cut-off: $22.5 \mathrm{bps}$ ), (AUC=0.673, $0.593-0.752$, with $74.7 \%$ sensitivity and $52.9 \%$ specificity, cut-off: 45.5 bps) and (AUC=0.674, $0.594-0.764$, with $93.1 \%$ sensitivity and $41.4 \%$ specificity, cut-off: $60.5 \mathrm{bps}$ ) respectively with CI $95 \%$ (Figure 4 ).

are determined by the balance between the excitatory sympathetic influence and the inhibitory parasympathetic influence. Sympathetic activity that increased during exercise reduces after finalizing exercise, however, recovery of the heart rate immediately after exercise is primarily a function of vagal reactivation, which is thought to be most important during the first minute after exercise [18]. In healthy and asymptomatic individuals, the heart rate falls rapidly within the first 30 seconds after exercise followed by a slower reduction [19]. In the case of presence of ischemia, ischemia-induced locally liberated adenosine, hydroxyl radicals and purinergic peptides can provoke modulations in both centripetal and centrifugal processing of intrathoracic nervous system [20]. Ischemia-induced cardio-cardiac reflexes and blunted baroreceptor reflexes result in dysfunction of cardiac autonomic nervous system and resulting deterioration of recovery of heart rate. Slower HRRI rates denote a significantly higher risk of death. HRRI, which is a simple and non-invasive method for evaluating sympathovagal balance, is not routinely evaluated in daily clinical practice even though it is an independent risk factor for cardiovascular diseases.

Because depressed vagal tone is associated with cardiovascular death, we hypothesized that decreased HRRI would be predictive of high SYNTAX score which is one of the major determinants of severity and mortality of CAD [21].

Airaksinen, et al. showed that cardiac vagal efferent activity is depressed in coronary artery disease even before the development of symptoms [22]. Also, a very rapid HR recovery immediately after exercise was found associated with lower risk of CHD and CVD events in a subanalysis of the Framingham Heart Study [1]. Vivekananthan, et al. [23] reported that HRR is an independent predictor of mortality along with angiographic severity of CAD, left ventricle function and exercise capacity.

Cole, et al. [24] studied 2428 adults who had been referred for exercise nuclear perfusion scans and they found that less than 12 bps decrease in heart rate in the 1st minute after exercise was associated with a relative risk of 2.0 for death from any cause over a 6-year period after adjustment of other cardiac risk factors (95\% confidence interval, 1.5-2.7; $\mathrm{p}<0.001)$. Current guidelines suggest that rapid supine patient placement after the exercise test offer advantages over other methods and should be considered [25]. A protocol with a staged cool-down walk was used in the aforementioned study. In our study, a protocol with prompt supine placement was used and ROC curve analysis determined the best cut-off value of HRRI1 as $22.5 \mathrm{bpm}$, with $75.9 \%$ sensitivity and $66.7 \%$ specificity to predict severe (Syntax $>33$ ) score. In a study of Akyuz, et al. no correlation was found between HRRI and Gensini scores and the number of coronary artery involvements, the only relationship was denoted between HRRI and the presence of CAD [26]. In our study, HRRI1 was directly correlated with high SYNTAX score which primarily defines severe CAD. Both after ROC curve analyses and partial correlation analyses adjusted for other possible confounders; HRRI1 and HRRI3 had significant, HRRI2 had moderate predictive values for high SYNTAX scores in patients with CAD. The most likely mechanism by which severe CAD affects HRRI is most likely due to the strong association between myocardial ischemia and cardiac autonomic dysfunction $[18,20]$.

\section{Conclusion}

Heart rate recovery can be defined as the rate at which the HR declines from either maximal or submaximal exercise to resting levels and has been identified as a powerful and independent predictor of cardiovascular and all-cause mortality in healthy adults. Our results point to the importance of the heart rate recovery in the identification of high CV risk patients and provides additional support for routine incorporation of heart rate recovery, at first minute, into standard risk stratification assessments among patients with suspected or documented CAD. Nevertheless, this is an observational and nonrandomized study; our results should be confirmed prospectively to confirm value of HRRI to predict CAD severity. 


\section{References}

1. Morshedi-Meibodi A, Larson MG, Levy D, O'Donnell CJ, Vasan RS (2002) Heart rate recovery after treadmill exercise testing and risk of cardiovascular disease events (The Framingham Heart Study). Am J Cardiol 90: 848-852. [Crossref]

2. Cole CR, Foody JM, Blackstone EH, Lauer MS (2000) Heart rate recovery after submaximal exercise testing as a predictor of mortality in a cardiovascularly healthy cohort. Ann Intern Med 132: 552-555. [Crossref]

3. Nishime EO, Cole CR, Blackstone EH, Pashkow FJ, Lauer MS (2000) Heart rate recovery and treadmill exercise score as predictors of mortality in patients referred for exercise ECG. JAMA 284: 1392-1398. [Crossref]

4. Safarian H, Alidoosti M, Shafiee A, Salarifar M, Poorhosseini H, et al. (2014) The SYNTAX Score Can Predict Major Adverse Cardiac Events Following Percutaneous Coronary Intervention. Heart Views 15: 99-105. [Crossref]

5. Farooq V, Brugaletta S, Serruys PW (2011) The SYNTAX score and SYNTAX-based clinical risk scores.Semin Thorac Cardiovasc Surg 23: 99-105. [Crossref]

6. Mendis S, Puska P, Norrving B (2011) (Eds) Global Atlas on Cardiovascular Disease Prevention and Control.

7. Lauer MS (2007) What is the best test for a patient with classic angina? Cleve Clin J Med 74: 123-126. [Crossref]

8. Gibbons RJ (2008) Noninvasive diagnosis and prognosis assessment in chronic coronary artery disease: Stress testing with and without imaging perspective. Circ Cardiovasc Imaging 1: 257-269. [Crossref]

9. Savonen KP, Kiviniemi V, Laukkanen JA, Lakka TA, Rauramaa TH, et al. (2008) Chronotropic incompetence and mortality in middle-aged men with known or suspected coronary heart disease. Eur Heart J 29:1896-1902. [Crossref]

10. Elamin MS, Mary DASG, Smith DR, Linden RJ (1980) Prediction of severity of coronary artery disease using slope of submaximal ST segment/heart rate relationship. Cardiovasc Res 14: 681-691. [Crossref]

11. Gibbons RJ, Balady GJ, Beasley JW, Bricker JT, Duvernoy WF, et al. (1997) ACC/ AHA guidelines for exercise testing: Executive summary: A report of the American College of Cardiology/American Heart Association task force on practice guidelines (Committee on exercise testing). J Am Coll Cardiol 30: 260-311. [Crossref]

12. Le VV, Mitiku T, Sungar G, Myers J, Froelicher V (2008) The blood pressure response to dynamic exercise testing: A systematic review. Prog Cardiovasc Dis 51: 135-160. [Crossref]

13. Leeper NJ, Dewey FE, Ashley EA, Sandri M, Tan SY, et al. (2007) Prognostic value of heart rate increase at onset of exercise testing. Circulation 115:468-474. [Crossref]
14. Buccelletti E, Gilardi E, Scaini E, Galiuto L, Persiani R, et al. (2009) Heart rate variability and myocardial infarction: systematic literature review and metanalysis. Eur Rev Med Pharmacol Sci 13: 299-307. [Crossref]

15. Kharabsheh S, Al-Sugair A, Al-Buraiki J, Al-Farhan J (2006) Overview of exercise stress testing. Ann Saudi Med 26: 1-6. [Crossref]

16. Dzenkeviciute V, Sapoka V, Kasiulevicius V, Rinkuniene E, Steponeniene R, et al. (2017) Value of Duke Treadmill Score in predicting coronary artery lesion and need of revascularisation. Kardiol Pol 75: 439-444. [Crossref]

17. Ardell JL (2001) Neurohumoral control of cardiac function. In: Heart Physiology and Pathophysiology, edited by Sperelakis N, Kurachi Y, Terzic A, and Cohen MV. New York: Academic 45-59.

18. Freeman JV, Dewey FE, Hadley DM, Myers J, Froelicher VF (2006) Autonomic nervous system interaction with the cardiovascular system during exercise. Prog Cardiovasc Dis 48: 342-362. [Crossref]

9. Imai K, Sato H, Hori M, Kusuoka H, Ozaki H, et al. (1994) Vagally mediated heart rate recovery after exercise is accelerated in athletes but blunted in patients with chronic heart failure. J Am Coll Cardiol 24: 1529-1535. [Crossref]

20. Armour JA (1999) Myocardial ischaemia and the cardiac nervous system. Cardiovasc Res 41: 41-54. [Crossref]

21. Kalla M, Herring N, Paterson DJ (2016) Cardiac sympatho-vagal balance and ventricular arrhythmia. Auton Neurosci 199: 29-37. [Crossref]

22. Airaksinen KE, Ikaheimo MJ, Linnaluoto MK, Niemela M, Takkunen JT (1987) Impaired vagal heart rate control in coronary artery disease. BR Heart J 58: 592-597. [Crossref]

23. Vivekananthan DP, Blackstone EH, Pothier CE, Lauer MS (2003) Heart rate recovery after exercise is a predictor of mortality, independent of the angiographic severity of coronary disease. J Am Coll Cardiol 42: 831-838. [Crossref]

24. Cole CR, Blackstone EH, Pashkow FJ, Snader CE, Lauer MS (1999) Heart-rate recovery immediately after exercise as a predictor of mortality. $N$ Engl J Med 341: 1351-1357. [Crossref]

25. Gibbons RJ, Balady GJ, Beasley JW, Bricker JT, Duvernoy WF, et al. (1997) ACC AHA guidelines for exercise testing: executive summary. A report of the American College of Cardiology/American Heart Association Task Force on Practice Guidelines (Committee on Exercise Testing). Circulation 96: 345-354. [Crossref]

26. Akyüz A, Alpsoy S, Akkoyun DC, Değirmenci H, Güler N (2014) Heart rate recovery may predict the presence of coronary artery disease. Anadolu Kardiyol Derg 14: 351 356. [Crossref]

Copyright: (C2018 Uzunget SB. This is an open-access article distributed under the terms of the Creative Commons Attribution License, which permits unrestricted use, distribution, and reproduction in any medium, provided the original author and source are credited. 